\title{
THE LATE CONSEQUENCES OF SCIATIC NERVE INJURY*
}

\author{
D. K. Clawsonf, Seattle, U.S.A., and H. J. Seddon, London, England \\ From the Institute of Orthopaedics, University of London
}

In the management of nerve injuries it is first necessary to determine whether the lesion is degenerative (neurotmesis or axonotmesis) or non-degenerative (neurapraxia). Paralysis that recovers quickly is due to neurapraxia and gives little trouble. Cases of sciatic neurotmesis and axonotmesis, or a combination of the two, have been studied to determine the late results with particular reference to permanent disability.

\section{THE PATIENTS AND THEIR INJURIES}

In the Nerve Injuries Unit at the Wingfield Morris Orthopaedic Hospital, Oxford, later transferred to the Institute of Orthopaedics, Royal National Orthopaedic Hospital, 401 patients with sciatic nerve injury were treated between 1940 and 1954 . Three hundred and twenty-nine patients have been followed for periods of between three and eighteen years; 143 were recalled for re-examination in connection with this report, and questionnaires were sent to the remainder to supplement the information available in the records. Included in the 329 are 118 cases of sciatic nerve repair which have been reported in another paper (Clawson and Seddon 1960). The site and nature of the lesions are shown in Table I.

\section{FUNCTIONAL GRADING}

Method of assessment-The neurological results were determined by the methods recommended in the Medical Research Council Report and summarised by Clawson and Seddon (1960).

The assessment of function is often difficult, because the patient's temperament and his reaction to the injury are important yet hard to define. One patient with a total sciatic lesion is a rock climber and has done some of the more difficult climbs in Switzerland. Another, with a total lateral popliteal paralysis, is a jet pilot in the Royal Air Force; he wears no apparatus, plays eighteen holes of golf and, despite a marked foot-drop, does not consider himself handicapped. At the other extreme, a patient with only slight lateral popliteal paresis insists on wearing toe-raising apparatus, says that he cannot walk more than a quarter of a mile because the leg tires, and for this reason feels that he is severely handicapped. We have taken into account the subjective complaints as well as the objective findings, while endeavouring to keep the classification of results as simple as possible. The following five grades of function have been devised; grades I to III are considered satisfactory:

Grade I Perfect foot or as good as the other.

Grade II Can walk any reasonable distance without pain; wears normal footwear and is fully active.

Grade III Can walk any reasonable distance with special shoes, pads or apparatus, with little or no pain; no disabling over-response to cutaneous stimuli; can follow his occupation.

Grade IV Can walk less than one mile; pain; very troublesome over-response; forced to accept less paying work because of the injury; pressure ulcers or sores.

Grade V Unable to work because of persistent pressure sores, ulcers or incapacitating pain; amputation.

\footnotetext{
* Presented at the Twenty-seventh Annual Meeting of the American Academy of Orthopaedic Surgeons in Chicago on January 20, 1960.

† This work was undertaken during the tenure of a Travelling Fellowship awarded by the National Foundation, United States. Dr Clawson is now head of the Division of Orthopaedics in the University of Washington, Seattle, Washington, U.S.A.
} 
RESULTS

Total sciatic paralysis-The results after total sciatic paralysis are shown in Table II. If the neurological is compared with the functional result it is found that, while 65 per cent of the patients with good motor recovery had satisfactory function, no less than 50 per cent of those

TABLE I

Clinical Detalls in 329 Cases of Sciatic Nerve Injury

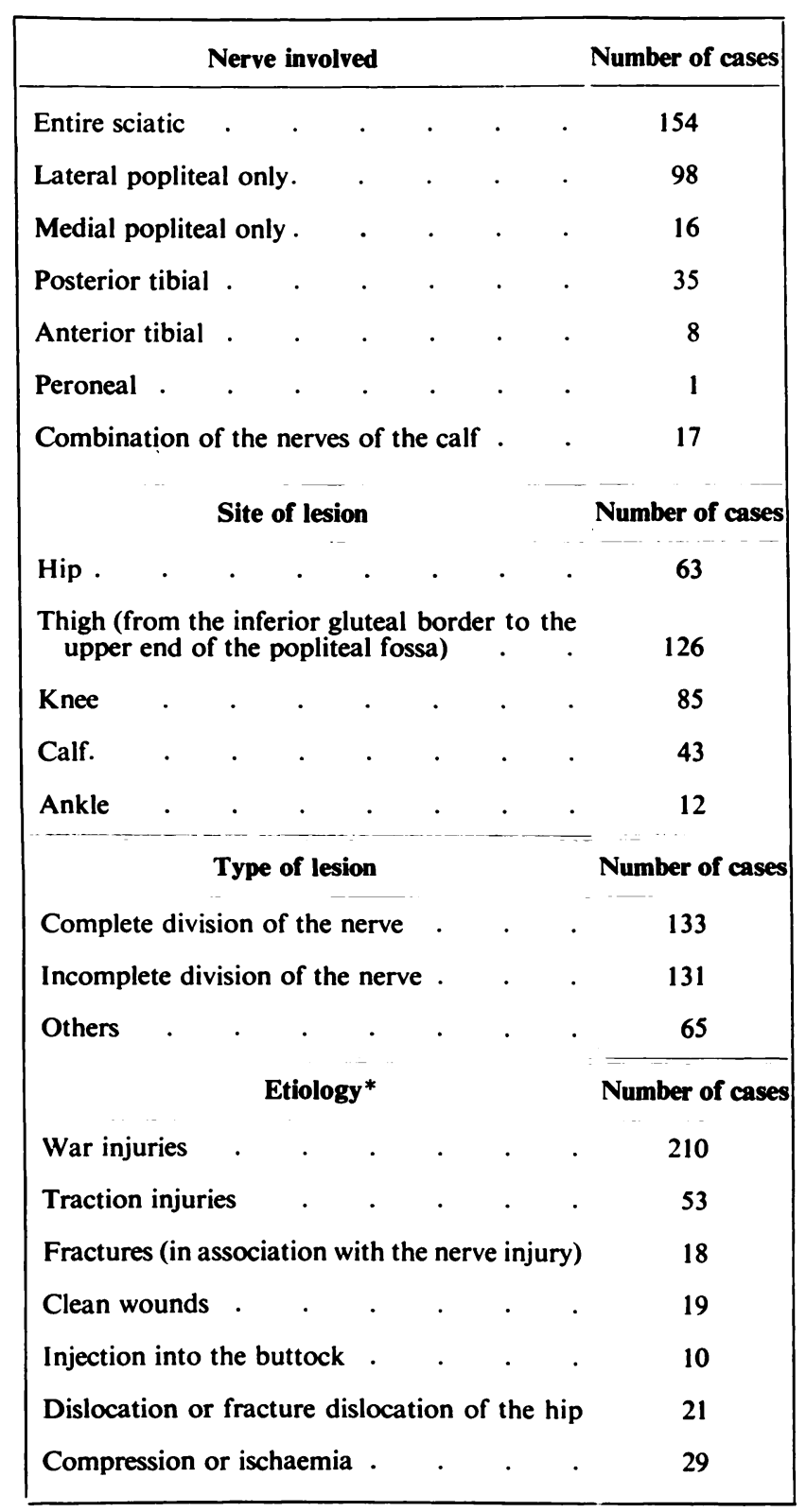

* In some cases there was more than one possible cause, which is the reason why this list adds up to 366 , thirty-seven more than the number of cases.

with poor motor recovery also had satisfactory function (Figs. 1 to 3 ). Function was satisfactory in 76 per cent of the patients with good sensory recovery, but in only 38 per cent of those with poor sensory recovery. Thus the functional result is not wholly dependent on the degree 

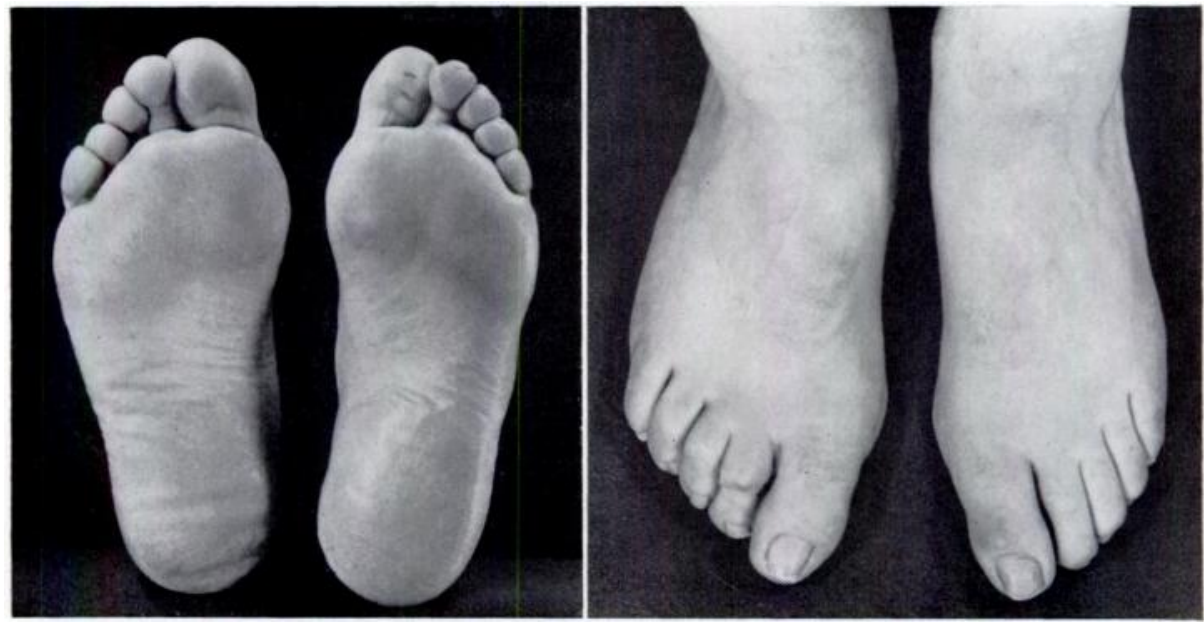

FIG. 1

Total left sciatic paralysis of fourteen years' duration. Sutured. Neurological recovery: medial popliteal-none; lateral popliteal-poor. Functional Grade III. Note the excellent condition of the foot with almost complete sciatic paralysis.

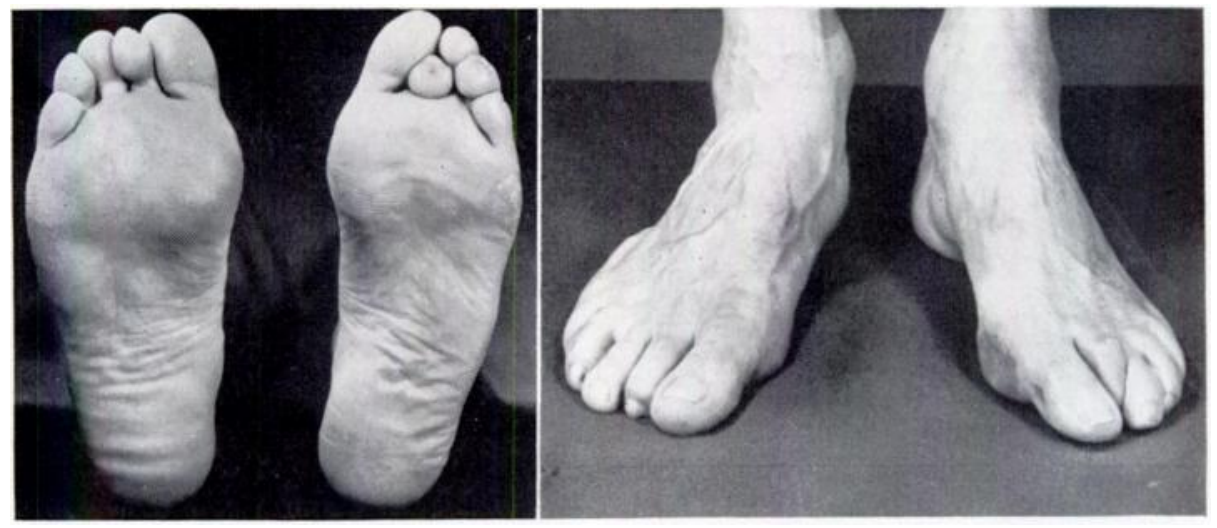

FIG. 2

Total left sciatic paralysis of sixteen years' duration. Sutured but no recovery. Functional Grade II Work panel wiring, very active; wears normal footwear. Hammer toe should be corrected.
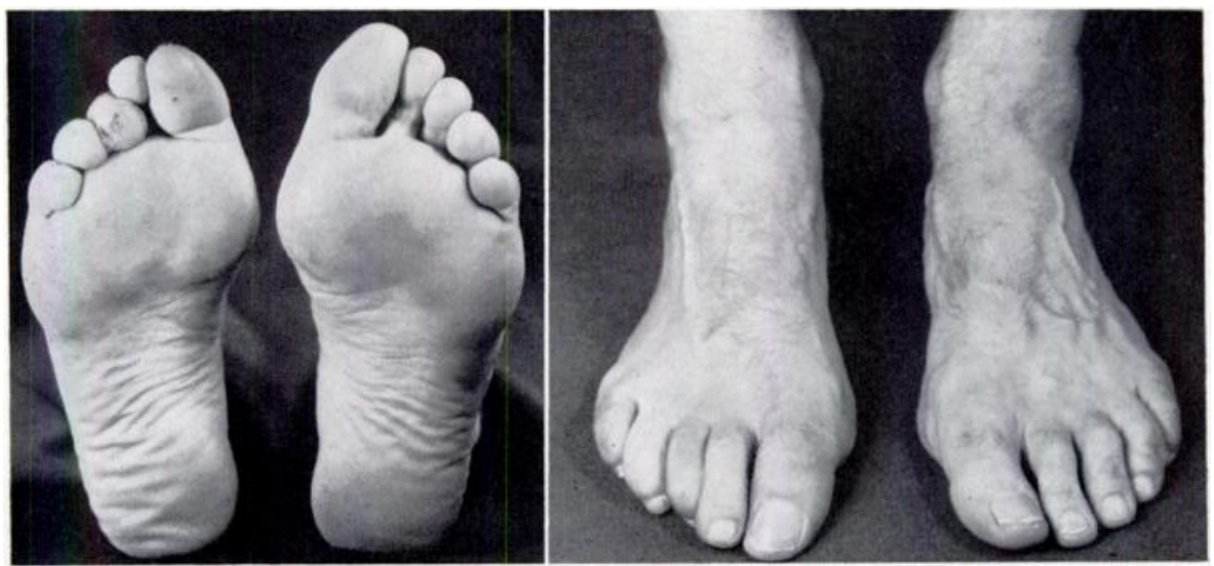

FiG. 3

Total right sciatic paralysis of thirteen years' duration. Sutured. Neurological recovery: most of the muscles of the leg act strongly, but only deep pain sensibility has returned. Functional Grade II.

Normal footwear, can walk ten miles. No complaints from clawing of toes or sore beneath the third toe 
of nerve recovery. One-third of the patients with no useful sensory recovery attained a satisfactory functional result; nevertheless, the better the nerve recovery, the better the function, though this applies more to sensory than to motor recovery.

Lateral popliteal nerve (Table III) - The correlation of nerve recovery with function is even less apparent in the lateral popliteal nerve where 83 per cent of the patients with poor motor recovery had satisfactory function as compared with 96 per cent of the patients with good

TABLE II

Results: Total Sciatic Paralysis

\begin{tabular}{|c|c|}
\hline Grade of functional recovery & Percentage of cases \\
\hline \multirow{5}{*}{ Satisfactory } & 07 \\
\hline & $12\} 64$ \\
\hline & 52 \\
\hline & 27 \\
\hline & 9 \\
\hline
\end{tabular}

TABLE III

Results: Lateral Popliteal Nerve

\begin{tabular}{c} 
Grade of functional recovery \\
\hline Satisfactory $\left\{\begin{array}{rr}\text { I } & \text { Percentage of cases } \\
\text { II } & 6 \\
\text { III } & 38 \\
\text { IV } & 45\end{array}\right\} 89$ \\
V \\
V
\end{tabular}

TABLE IV

Results: Medial Popliteal Nerve

\begin{tabular}{|cc|}
\hline Grade of functional recovery & Percentage of cases \\
\hline Satisfactory $\left\{\begin{array}{rr}\text { I } & 4 \\
\text { II } & 30 \\
\text { III } & 53\end{array}\right\} 87$ \\
IV & 13 \\
V & 0 \\
\hline
\end{tabular}

motor recovery. Eighty per cent of the patients with poor sensory recovery had satisfactory function compared with 92 per cent of the patients with a good sensory result (Fig. 4). Few people with this lesion are permanently handicapped. Only 11 per cent had unsatisfactory function; however, the better the nerve recovery the better the function.

Medial popliteal nerve (Table IV)-Here there is a surprising lack of correlation between nerve recovery and good function (Fig. 5); 86 per cent of the patients with good motor recovery and 85 per cent of those with poor motor recovery had a satisfactory functional result. There was no closer correlation with sensory recovery; whether it was good or bad 85 per cent of the patients showed a satisfactory functional result. Medial popliteal paralysis is not as severe a handicap as might be expected, though the better grades of functional recovery were seen in those patients with better nerve recovery.

TYPES OF INJURY

Although war injuries predominated, brief reference must be made to other types of damage, which might have a bearing on prognosis. In the following paragraphs only the quality of neurological recovery is referred to. 

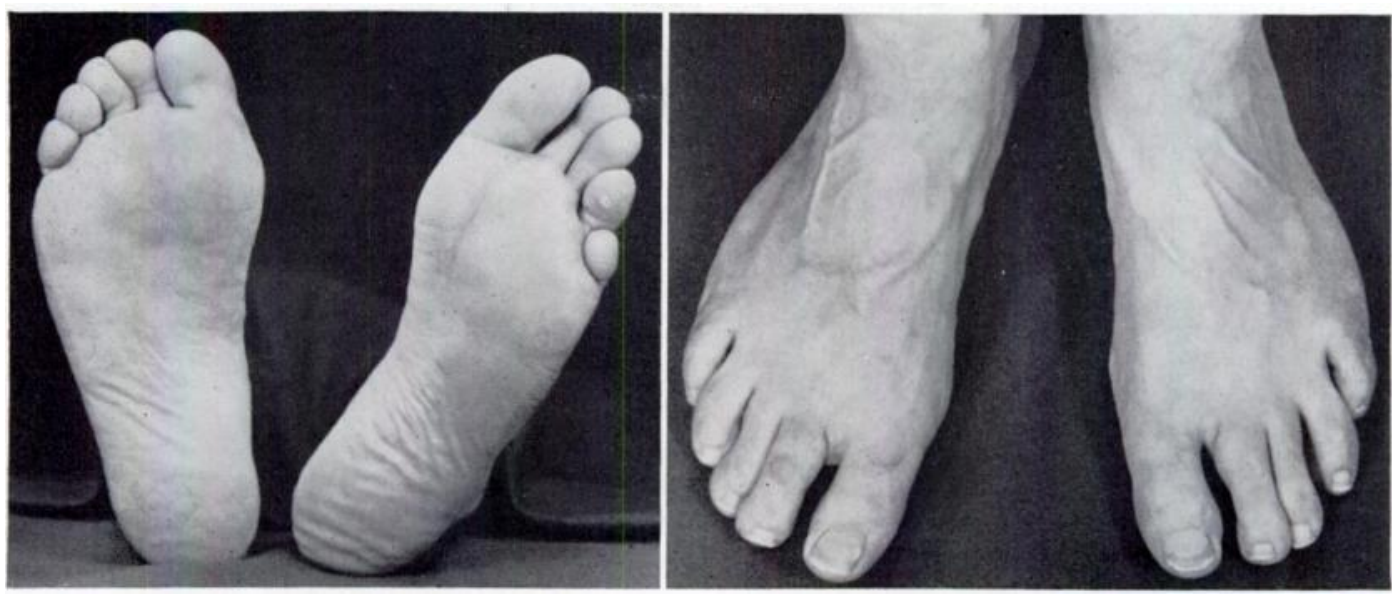

Fig. 4

Left lateral popliteal paralysis of thirteen years' duration. Eight centimetre gap. No repair. No motor recovery but good sensibility. Functional Grade III. Wears toe-raising appliance.
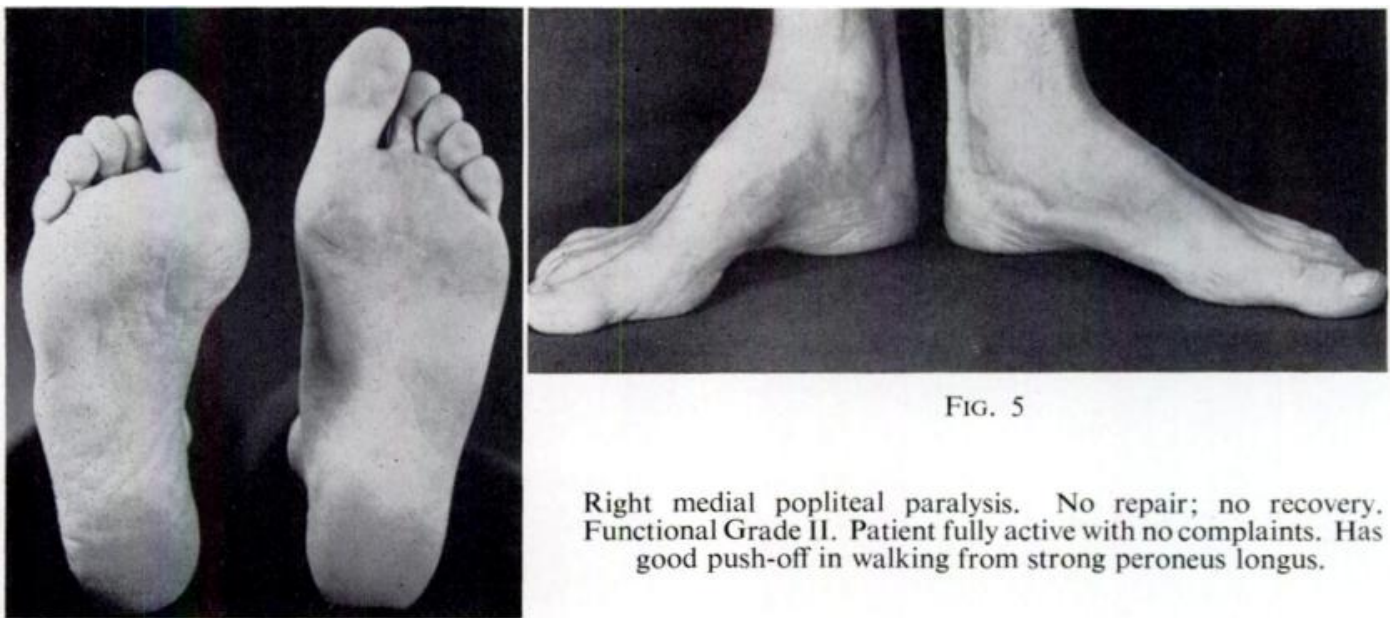

FIG. 5

Right medial popliteal paralysis. No repair; no recovery. Functional Grade II. Patient fully active with no complaints. Has good push-off in walking from strong peroneus longus.

Clean wounds-In nineteen cases there were clean wounds, eight involving the posterior tibial nerve. The quality of recovery was well above the average: in four-fifths of the cases there was some motor recovery and there was useful sensory recovery in all: Nevertheless, two-thirds of these patients exhibited symptoms due to sensory over-response.

Injection injuries-There were ten sciatic nerve injuries due to injections into the buttock, and in seven both divisions of the nerve were involved. The substances injected were quinine and atebrin, one case; heparin, one case; and sulphonamide compounds in eight cases. All patients showed some recovery but in none was it complete. The variability of recovery was such that the initial degree of paralysis gave no indication of what the final recovery would be.

Pressure-There were seven cases of lateral popliteal paralysis due to pressure in which a complete reaction of degeneration was present. In all there was useful sensory recovery and in four satisfactory motor recovery.

Ischaemia-There were eight cases in which ischaemia of nerves in the calf was the cause of the paralysis. In four there was excellent motor recovery and in five a satisfactory return of sensibility.

VOL. 42 B, NO. 2, MAY 1960 
Traction injuries (Table V)-Fifty-three traction injuries were studied and in thirteen the nerve was explored. Unless complete rupture was revealed the appearance of the nerve gave no clue to the prospects of recovery. The prognosis was unaffected by exploration. The quality of recovery was a little above the average.

TABLE V

Recovery after Traction Lesions

\begin{tabular}{|c|c|c|c|c|c|c|}
\hline \multirow{2}{*}{$\begin{array}{l}\text { Level } \\
\text { of } \\
\text { lesion }\end{array}$} & \multirow{2}{*}{$\begin{array}{c}\text { Number } \\
\text { of } \\
\text { cases }\end{array}$} & \multirow{2}{*}{ Nerve } & \multicolumn{2}{|c|}{ Functional motor recovery } & \multicolumn{2}{|c|}{ Functional sensory recovery } \\
\hline & & & $\begin{array}{l}\text { Traction } \\
\text { (per cent) }\end{array}$ & $\begin{array}{l}\text { All cases } \\
\text { (per cent) }\end{array}$ & $\begin{array}{l}\text { Traction } \\
\text { (per cent) }\end{array}$ & $\begin{array}{l}\text { All cases } \\
\text { (per cent) }\end{array}$ \\
\hline \multirow{2}{*}{ Hip } & \multirow{2}{*}{27} & Lateral popliteal component (21) & 52 & 44 & 95 & 73 \\
\hline & & Medial popliteal component (18) & 83 & 70 & 89 & 75 \\
\hline Knee & 26 & Lateral popliteal & 58 & 52 & 85 & 80 \\
\hline
\end{tabular}

\section{FACTORS INFLUENCING THE FUNCTIONAL RESULT}

Age of patient-As most of these patients had suffered war injuries most were young adults. There were only fourteen patients under fifteen years of age and thirty-seven over thirty-five. There are too few cases in these two groups to permit comparison but it appears that age has little influence on nerve regeneration. However, functional recovery was better in the younger patients. After nerve suture in children sensory recovery is of better quality than in the adult. In the elderly, factors other than the nerve injury frequently influence the functional result.

TABLE VI

incidence of Pain in Relation to Site of Lesion

\begin{tabular}{|c|c|}
\hline Nerve injured & Percentage of patients with pain \\
\hline Sciatic . & 58 \\
\hline Medial popliteal & 56 \\
\hline Lateral popliteal & 43 \\
\hline Level of lesion & Percentage of patients with pain \\
\hline Hip. & 64 \\
\hline Thigh & 48 \\
\hline Knee & 46 \\
\hline Calf and ankle & 64 \\
\hline
\end{tabular}

\section{SENSORY PHENOMENA}

Pain (Table VI)-Pain is the most common complaint of patients with sciatic nerve injury and was present in 175 cases ( 53 per cent). It was variously described as a deep or a constant ache; aching when tired, or with temperature change; a throbbing or dull nagging pain. In addition, there were three patients in this series with typical causalgia treated by sympathectomy with marked relief of symptoms. A study of these three cases adds nothing to what has already been reported on this subject. 
There is no correlation between pain and the nerve involved or the site of the lesion. The same is true of the type of lesion; thus 57 per cent of patients with traction lesions, 52 per cent of those whose nerves had been sutured, and 53 per cent of all patients had pain. There is no relationship between pain and nerve recovery. The pain is, however, generally less severe in patients with little or no recovery; and it is less marked in those with good recovery than in the larger middle group with partial recovery.

Paraesthesiae-Paraesthesiae-tingling, pins and needles and burning-were noted in 21 per cent of all patients in this series. No particular reason for their occurrence could be found. Over-response-This term is used to describe an exaggerated and painful response to an ordinary stimulus. It can vary from a very uncomfortable sensation when walking to complete

TABLE VII

OVER-RESPONSE

\begin{tabular}{|lccccc|}
\hline $\begin{array}{c}\text { Level of } \\
\text { lesion }\end{array}$ & $\begin{array}{c}\text { Number of } \\
\text { patients with } \\
\text { over-response }\end{array}$ & $\begin{array}{c}\text { Lateral } \\
\text { popliteal } \\
\text { division }\end{array}$ & $\begin{array}{c}\text { Medial } \\
\text { popliteal } \\
\text { division }\end{array}$ & $\begin{array}{c}\text { Percentage of } \\
\text { total patients in } \\
\text { each group with } \\
\text { over-response }\end{array}$ \\
\hline Hip . & 22 & 3 & 19 & 37 \\
Thigh & 57 & 0 & 57 & 55 \\
Knee & 14 & 6 & 8 & 40 \\
Calf. & 15 & 1 & 14 & 47 \\
Ankle &. & 8 & 0 & 8 & 67 \\
\hline
\end{tabular}

inability to bear weight on the foot unless it is protected by a thick rubber pad in the shoe. The most frequent complaints were inability to walk without special shoes, and severe pain when stepping on an irregular surface. Walking along a beach or climbing a ladder was impossible. None of the patients with over-response felt that it was regressing with time, but many had learned to adjust themselves to it. Most of them were reasonably comfortable when wearing a heavy-soled shoe containing a thick sponge rubber pad.

When over-response is present the limb is sharply withdrawn if the affected area is stroked, or pricked with a pin. Thirty-five per cent of all patients, 54 per cent of those with medial popliteal lesions and only 3.5 per cent of those with lateral popliteal lesions presented this sign. In 4 per cent of patients with total medial popliteal paralysis who complained of overresponse, the sensitive zone was at the periphery of the saphenous area on the sole.

Because over-response is disabling, its absence or disappearance is one of the conditions for good sensory recovery.

The relationship of over-response to the level of the lesion has a bearing on the desirability of repair of a severed nerve (Table VII).

Eight of the twelve patients with posterior tibial lesions at the ankle exhibited overresponse. Of the four who did not, one had complete insensibility of the sole following wide resection of the nerve; another, an adult of twenty-four years, was treated by early secondary suture following a clean wound; and the other two were children eight and twelve years of age. Over-response may be a troublesome feature after nerve suture at any level in the lower limb. After suture at the level of the hip or in the thigh the benefit from the return of power in the calf muscle may outweigh the risk that over-response may develop. But it is questionable whether distal lesions of the posterior tibial nerve should be repaired unless conditions are very favourable. In these patients an anaesthetic sole is of little consequence if the saphenous 
and sural nerves are intact. Motor recovery in the foot after posterior tibial nerve suture is functionally useless. Perhaps posterior tibial nerve suture should be done only in children. Sensory recovery by overlap-The behaviour of the zone of cutaneous sensory loss presents some interesting features. There is much individual variation in the area supplied by a particular sensory nerve. There is also the phenomenon of shrinkage of the anaesthetic area which occurs in the absence of regeneration and is due to the ingrowth of nerve fibres from the adjacent normally innervated skin (Weddell, Guttmann and Gutmann 1941).

In this series there were six patients with large gaps in the medial or lateral popliteal nerves (5-9 centimetres) where no repair was attempted, yet fair sensibility returned in the entire denervated zone (Fig. 4). Twenty-nine other patients with complete and irreparable lesions showed no motor recovery, but there was fair sensory recovery. We do not know whether this is due to the ingrowth of fibres from adjacent innervated zones or to re-innervation by sensory fibres which have " jumped the gap." Nerve biopsy distal to the lesion and nerve block above it should provide the answer.

\section{VASOMOTOR AND TROPHIC DISORDERS}

The vasomotor and trophic changes following a nerve lesion are well known. They may be present initially and disappear, whereas in some patients they may become progressively more prominent.

It is important to examine the degree to which these complaints may be disabling and their relationship to other phenomena. One-third of all patients studied showed some of the following changes. Most complained of coldness of the affected limb; others exhibited erythema, pigmentation, thin shiny skin, nail changes and oedema.

Although initially the skin temperature is raised owing to the autonomic paralysis, it soon becomes and remains subnormal. None of the patients in this study showed increased warmth of the extremity except those with partial lesions who had been subjected to sympathectomy. Coldness of the affected limb was present in 95 per cent of patients with vasomotor or trophic complaints. It was often associated with an ache and, while never disabling, some patients found it annoying and disagreeable. Sixty-nine per cent of all patients with involvement of

TABLE VIII

VASOMOTOR AND TROPHIC DisORders

\begin{tabular}{|llc|}
\hline Level & & $\begin{array}{c}\text { Percentage of cases } \\
\text { at each level }\end{array}$ \\
\hline Hip . & $\cdot$ & 65 \\
Thigh &. & 58 \\
Knee &. & 34 \\
Calf. & $\cdot$ & 42 \\
Ankle &. & 25 \\
\hline
\end{tabular}

both divisions of the sciatic nerve exhibited vasomotor and trophic disorders. Seventy-one per cent of patients with medial popliteal lesions, and 35 per cent of those with lateral popliteal lesions were similarly affected. Patients with lesions in continuity had fewer complaints than those with complete division, regardless of the eventual degree of nerve recovery. There was no correlation between motor recovery and the incidence of vasomotor and trophic disorders; good motor recovery occurred in roughly half the cases, whether or not these changes were present. As would be expected, there was a connection between sensory recovery 
and vasomotor and trophic disorders: when the latter were present good sensory recovery had occurred in 46 per cent of the patients, whereas 85 per cent of patients without such complaints showed good sensory recovery.

Vasomotor and nutritional changes are more severe in proximal than distal lesions (Table VIII).

The complaint of coldness is attributed to the vaso-constrictor action of low temperature on denervated blood vessels (Lewis and Landis 1930). It is less liable to be present where there has been good sensory recovery because the autonomic fibres run and regenerate with the sensory. However, this may not be the whole answer. In poliomyelitis coldness of a limb, although a direct result of increased peripheral vascular tone (Trott, Nesline and Green 1958). is certainly closely associated with motor paralysis. In paralysis caused by nerve injury the skin disorders and nail changes may to some extent be consequent on the motor paralysis.

\section{PRESSURE SORES}

A pressure sore is the most serious consequence of sciatic nerve injury, but its incidence is less than is commonly believed. Forty-five patients (14 per cent) suffered from pressure sores at some time or other. In forty-three the sciatic nerve was damaged; in two the lateral popliteal alone, but in both of these the ulceration was due to factors other than the nerve injury; one ulcer developed over a splitskin graft and the other was caused by a plaster used to treat a fracture nine years after the nerve injury.

In thirty-eight cases-88 per cent of the forty-five-the sore appeared within two years of the nerve injury. In twelve it was caused by a plaster or splint; all but two of these healed promptly without recurrence. Nineteen of the thirty-eight patients continued to have trouble for longer than four years, some for as long as they were followed. In all of them fixed deformity was the main contributory factor (Figs. 3 and 6). Patients with no sensibility in the sole were twice as prone to ulceration as patients with good sensory recovery; yet in over half the patients with persistent ulceration there was fair

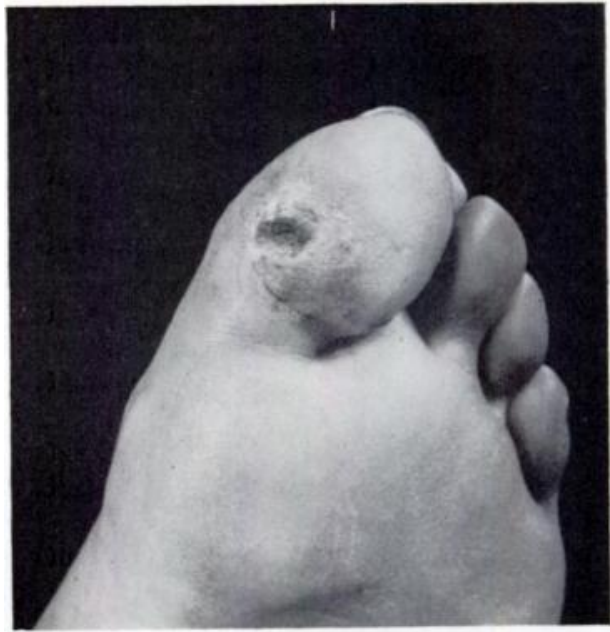

Fig. 6

Total sciatic paralysis; lateral popliteal graft to medial popliteal nerve. Calf muscle strong; pain sensibility alone in the sole. Persistent ulcer on the great toe due to a contracture in 10 degrees of flexion. sensibility in the sole.

Impairment or loss of sensibility in the sole of the foot is far less important than fixed deformity. Every patient with persistent ulceration also suffered from fixed deformity of the foot or toes.

\section{PALLIATIVE SURGERY}

Tarsal arthrodesis-The commonest reconstructive operation for sciatic palsy was the Lambrinudi arthrodesis for foot-drop, which was performed in twenty cases. Only half of the patients were satisfied with the result.

The criteria of success were: 1) correction of the foot-drop, 2) no more pain in the foot than before the operation, and 3) function at least as good as before the operation. By this standard the operation was successful in only five-one-quarter-of the cases. The complaints in the fifteen unsuccessful cases were: more pain (thirteen patients); varus deformity causing symptoms (ten patients); swelling of the ankle (four patients); foot-drop greater than 30 degrees 
(four patients); still wearing apparatus (three patients); poorer function after the operation (three patients).

Analysis of the unsuccessful cases explains the shortcomings of the Lambrinudi operation. Technical failures might explain some of the difficulties, but this does not alter the basic weaknesses of the procedure.

Pain-The pain was centred in one of three places: 1) about the ankle joint; 2) over the dorsum of the foot where in three cases radiography demonstrated non-union between the

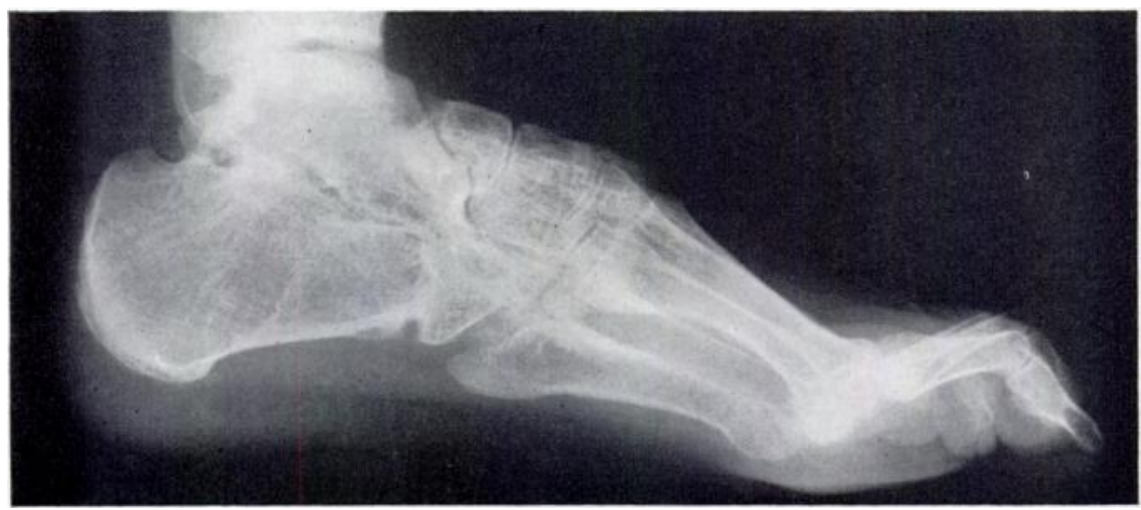

Fig. 7

Lambrinudi arthrodesis for foot-drop. Pain and slight swelling over fibrous union between talus and navicular bone.

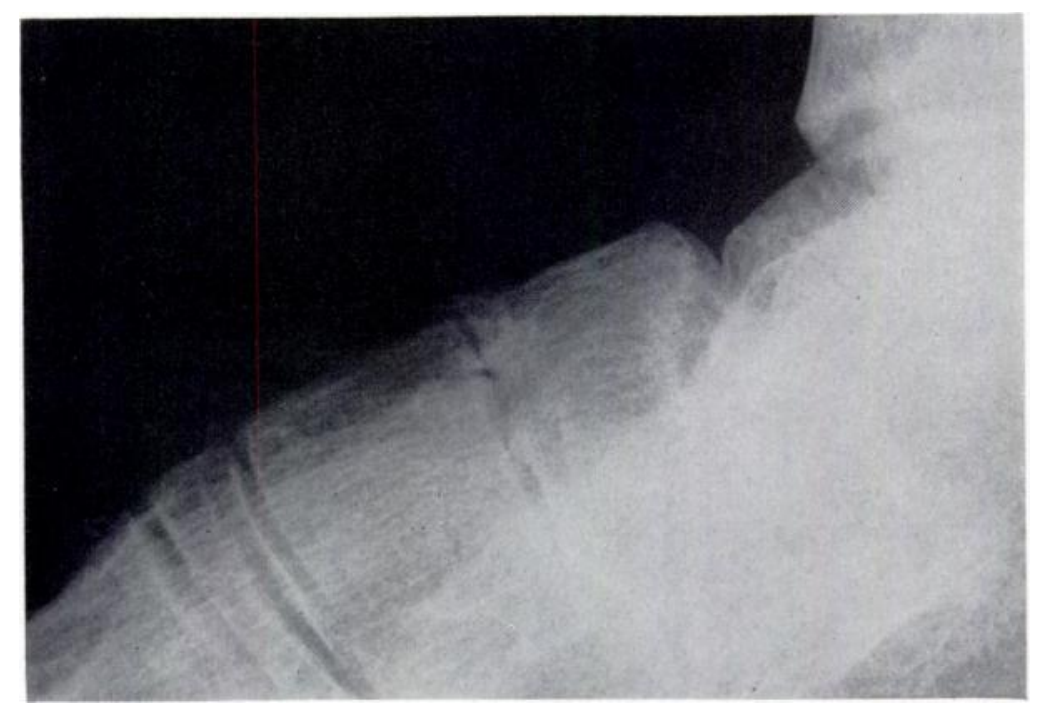

FIG. 8

Lambrinudi arthrodesis for foot-drop. There was an ache across the dorsum of the foot aggravated by walking. Note degenerative changes in navicular-cuneiform joint.

talus and the navicular bone (Fig. 7); another possible cause of pain over the dorsum of the foot was increased strain of the mid-tarsal joints with secondary arthritis (Fig. 8); 3) about the lateral malleolus where the decreased height of the foot caused the lateral malleolus to impinge on the calcaneum or to rub on the top of the shoe.

Swelling-It is not certain what causes persistent post-operative swelling. It may be associated with failure of fusion or be secondary to arthritic changes. 
Persistence of foot-drop-Sometimes the foot-drop, although corrected initially, reappeared. This was due to stretching of the medial and lateral ligaments of the ankle which allowed the joint to open anteriorly (Fig. 9). Less commonly, the forefoot also may become more plantarflexed.

Fixed deformity-If the usual pattern of weight bearing is important in the normal foot, it is more so after tarsal arthrodesis, which abolishes the lateral movement required when the patient is walking on an irregular surface; and even more so if the sole of the foot is more or less insensitive. A varus deformity after Lambrinudi's arthrodesis is due to inaccurate operative technique, and adds greatly to a patient's disability (Fig. 10). A supple foot with no deformity even though paralysed is far better than a fixed deformed foot that does not drop.

Functionally worse after operation-If the results of the Lambrinudi operation were

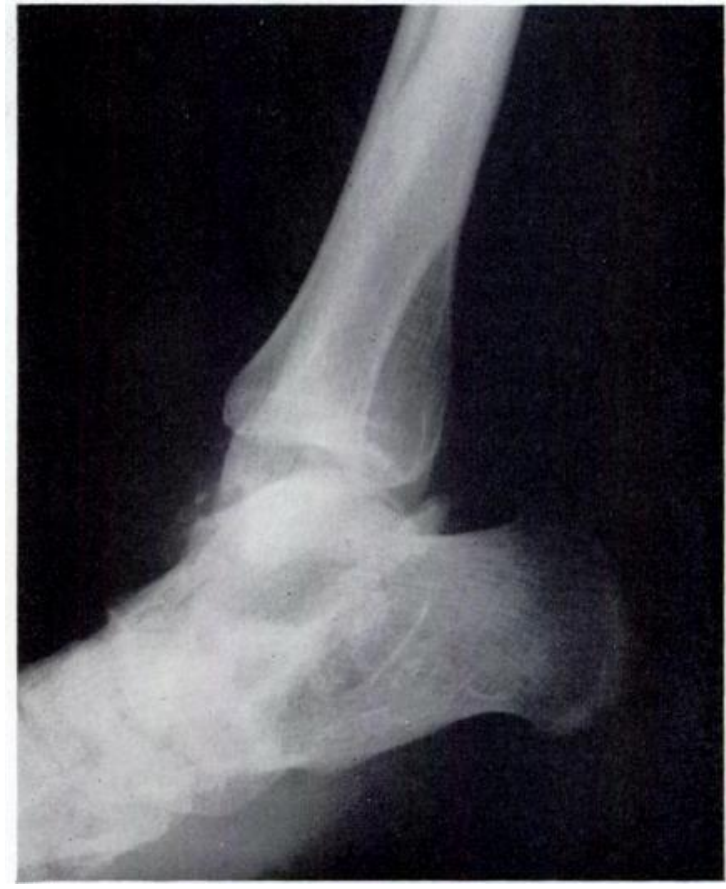

Fig. 9

Lambrinudi arthrodesis for foot-drop. The ankle joint opens anteriorly.

judged only on the ability of the patient to dispense with apparatus because the foot-drop had been controlled, 80 per cent of the cases could be considered satisfactory. Yet, as has been shown, only a quarter of the patients were satisfied. The observation that the foot was less useful after the operation came from men who had worn apparatus for some years before the stabilisation had been performed. They had been able to walk fast, cover considerable distances without tiring, and even run without stumbling. They had had less discomfort with the apparatus. Many patients at various times had been asked if they would like an

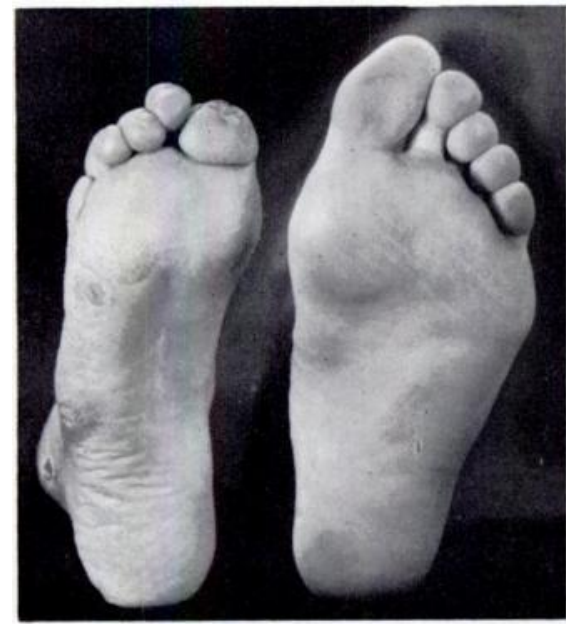

Right sciatic injury ten years previously. Repaired by a graft from the lateral popliteal nerve to the medial popliteal. Calf muscle aching strongly but only deep pain sensibility in the sole. Lambrinudi arthrodesis. Pressure over the fifth metatarsal head necessitated its removal. Callosities over neck and base of fifth metatarsal and severe claw toes. 
operation to rid them of apparatus they had worn for five years or more. All the men had refused on the grounds that the apparatus was little or no handicap. Women, however, were more conscious of the ugliness of the apparatus and were in favour of operation.

It is evident that for the treatment of sciatic paralysis Lambrinudi's operation is so unreliable that it should be advised only with great caution.

Tenodesis-While it was recognised that tenodesis for foot-drop had been a failure in children, it was considered justifiable to give the operation a trial in adults as a time-saving measure. There was great pressure to return men to military service as quickly as possible. Accordingly, fixation of the tendons of the tibialis anterior and peroneus longus into the tibia was performed in five cases. Only one patient had an excellent result; he even was able to play hockey for two seasons without difficulty. In the others the foot-drop soon recurred and the operation was therefore discarded.

Tendon transplantation-Transfer of the posterior tibial tendon through the interosseous membrane to the dorsum of the foot (Watkins, Jones, Ryder and Brown 1954) has been used in cases of lateral popliteal paralysis. In this series there were four examples of this operation in which the period of post-operative observation was three years or more, and in all four cases the functional result was excellent. There have so far been no failures in twelve subsequent cases. The operation abolished the deforming pull of the tibialis posterior and restored active dorsiflexion of the foot. It is still questionable whether this active dorsiflexion takes place when the patient is walking, but it certainly eliminates the foot-drop. It has yet to be decided whether it is best to attach the tendon to the mid-dorsum of the foot or to the extensors of the toes.

Correction of claw toes-The commonest deformity is the claw toe which was present in one-third of all cases (Figs. 2, 3 and 10). It is usually a consequence of medial popliteal paralysis; in only ten cases - 9 per cent-was the lateral popliteal nerve alone affected. It is uncommon after complete nerve lesions. Fifty-four per cent of cases of clawed toes followed incomplete lesions of the medial popliteal nerve; 31 per cent were after nerve suture. Thirteen patients were treated by arthrodesis of the proximal interphalangeal joints and the results were excellent.

In view of the peculiarly disabling consequences of deformity of the more or less anaesthetic foot no time should be lost before incipient deformity is corrected; it is best to intervene before operations involving bone resection become necessary.

Amputation-In the past, amputation was often thought to be the inevitable fate of patients with complete sciatic nerve lesions. This defeatist attitude is unjustified. Ten amputations were carried out on patients in this series. In nine there had been a total sciatic lesion initially. There was no motor recovery in five cases, partial recovery in four, and useful recovery in only one case. Six patients showed no sensory recovery. Satisfactory sensory recovery does not preclude the possibility of amputation but it is less likely to be necessary than in patients with total sensory loss.

Reasons for amputation-These were: 1) stiff foot with fixed deformity (eight cases); 2) pressure sores (seven cases); and 3) pain (five cases-causalgia, one; hypersensitivity, one).

Patients' response to amputation-Five patients were satisfied with the result, three were not and two offered no comment. The patients on whom the operation was carried out for fixed deformity with secondary ulceration were extremely happy. The three dissatisfied patients had undergone amputation for pain and, unfortunately, as might be expected, the pain did not improve. There should, therefore, be little reason for amputation of the leg after sciatic nerve injury. If pain is present it is unlikely to be relieved; with proper treatment from the beginning to prevent stiffness and deformity there should be no reason for amputation on this account. 


\section{SUMMARY}

1. We have described what happens to patients a number of years after injury of the sciatic nerve or of its divisions; there were 329 who had been under observation for periods ranging from three to eighteen years. The neurological recovery was recorded in every case and, more important, the behaviour of the limb as appreciated by the patient.

2. Although it was generally true that good neurological recovery and good function went together there were remarkable discrepancies. Isolated paralysis of the medial popliteal or of the lateral popliteal nerve was often compatible with good function, though patients with lateral popliteal paralysis usually needed toe-raising apparatus. Even total sciatic paralysis sometimes gave little trouble.

3. Of the various types of injury, clean wounds and traction lesions led to rather better than average return of function.

4. Some degree of pain was present in about half the cases, and over-response-exaggerated and painful response to an ordinary stimulus-was present in one-third of the cases.

5. Repair of the posterior tibial nerve was rarely worth while; no less than eight out of twelve patients with this type of injury exhibited over-response.

6. One-third of the patients showed vasomotor and trophic disorders: coldness of the affected limb, erythema, thinness or pigmentation of the skin, changes in the nails or oedema.

7. Pressure sores were the most serious consequence of sciatic nerve injury and at some time or other were present in 14 per cent of our patients. The cause was deformity rather than insensibility of the sole.

8. Of the various palliative operations Lambrinudi's tarsal arthrodesis gave such disappointing results that we doubt whether the operation is worth doing. Tenodesis, revived as a timesaving expedient during the war, was a failure. For lateral popliteal paralysis anterior transplantation of tibialis posterior is excellent.

9. Amputation was done in only ten cases. When it was performed for fixed deformity with secondary ulceration the result was satisfactory. When it was done because of pain there was no relief. Amputation is, therefore, avoidable provided that vigorous steps are taken to prevent or correct deformity; it should not be done for the relief of pain.

\section{REFERENCES}

Clawson, D. K., and Seddon, H. J. (1960): The Results of Repair of the Sciatic Nerve. Journal of Bone and Joint Surgery, 42-B, 205.

Lewis, T., and LaNDis, E. M. (1930): Some Physiological Effects of Sympathetic Ganglionectomy in the Human Being and its Effect in a Case of Raynaud's Malady. Heart, 15, 151.

Trott, A. W., Nesline, M. D., and Green, W. T. (1958): The Chronology of Circulatory Changes in Poliomyelitis. Journal of Bone and Joint Surgery, 40-A, 245.

Watkins, M. B., Jones, J. B., Ryder, C. T., Jun., and Brown, T. H., Jun. (1954): Transplantation of the Posterior Tibial Tendon. Journal of Bone and Joint Surgery, 36-A, 1,181.

Weddell, G., GuttmanN, L., and GutmanN, E. (1941): The Local Extension of Nerve Fibres into Denervated Areas of Skin. Journal of Neurology and Psychiatry, N.S. 4, 206. 